\title{
Kernos
}

Revue internationale et pluridisciplinaire de religion grecque antique

3| 1990

Varia

\section{Maria ROCCHI, Kadmos e Harmonia. Un matrimonio problematico}

\author{
Vinciane Pirenne-Delforge
}

URL : http://journals.openedition.org/kernos/1034

DOI : $10.4000 /$ kernos. 1034

ISSN : 2034-7871

\section{Éditeur}

Centre international d'étude de la religion grecque antique

\section{Édition imprimée}

Date de publication : 1 janvier 1990

ISSN : 0776-3824

\section{Référence électronique}

Vinciane Pirenne-Delforge, "Maria RoccH, Kadmos e Harmonia. Un matrimonio problematico », Kernos [En ligne], 3 | 1990, mis en ligne le 19 avril 2011, consulté le 24 septembre 2020. URL : http:// journals.openedition.org/kernos/1034; DOI : https://doi.org/10.4000/kernos.1034 
de Démosthène : dans les termes radicaux qui servent à sa présentation, cette thèse ne nous convainc pas, même si nous reconnaissons le poids de certains arguments. Il faudra aussi tenir compte d'une interprétation dionysiaque des aspects mystiques du culte, interprétation qui, si elle n'est pas confirmée par les données épigraphiques (il s'agit d'une affinité typologique et non d'une réelle association cultuelle), ne se fonde pas non plus uniquement sur un malentendu : nous n'acceptons donc pas l'idée de l'A. qui pense avoir expliqué dans ce dernier chapitre "how a literary tradition can arise, flourish, and continue for centuries completely divorced from reality" (p. 60).

Ces quelques objections ponctuelles ne doivent pas faire oublier l'utilité d'une synthèse fondée sur une bonne connaissance de tous les témoignages du culte, synthèse dont l'absence se faisait sentir.

Fabio MORA

Maria ROCCH, Kadmos e Harmonia. Un matrimonio problematico, Roma, 'L'Erma' di Bretschneider, 1989, 144 p., 17 x $24 \mathrm{~cm}$. (Storia delle religioni, 6). ISBN : 88-7062-648-2.

Le mariage de Kadmos et d'Harmonie fait partie des événements fondateurs du cosmos; c'est ce que montre l'analyse très fine de $\mathrm{M}$. Rocchi dans ce petit ouvrage très stimulant. Conformément à la méthodologie de l'«École de Rome», le mythe est étudié pour lui-même et par lui-même, le sens se révélant de la confrontation des variantes que la tradition fournit en relation avec l'événement en question. Les éléments fondamentaux du récit sont abordés successivement: espace, temps, personnages, action dans la fête.

Selon les traditions, la noce s'est déroulée soit près du lac Tritonis en Libye, soit dans l'île de Samothrace ou encore à Thèbes. Chaque lieu possède des prérogatives mythiques qui les caractérisent de manière univoque : le lac et l'île sont proches du ciel, aux marges du monde, Thèbes est également céleste, comme le montre la conformation de sa muraille aux sept portes. Mais tandis que les conditions de la vie des Bienheureux se poursuivent dans l'île et au bord du lac, dans la cité fondée par Kadmos, le temps des hommes succède à celui des Bienheureux au terme de la cérémonie du mariage.

Le héros, par son mariage, instaure une harmonie nouvelle, un lien particulier entre les hommes et les dieux, lien qui fonde le cosmos grec (le fait que Kadmos appartient à un temps où ce cosmos n'est pas encore constitué justifierait, d'après l'A., son origine proche-orientale : il ne peut venir que d'un autre espace). Quant à Harmonie, son rôle correspond au champ sémantique recouvert par son nom : elle est l'harmonie qui unit deux mondes désormais inexorablement différents. Au cours des noces sont posés des actes séparateurs (don du blé par Déméter et définition des domaines humain et divin dans l'exercice de la 
musique), mais ce mariage paradigmatique fournit également aux hommes un modèle dans la conformité duquel ils pourront dépasser la mort à travers leurs enfants. Par ailleurs, l'union de Kadmos et d'Harmonie constitue le postulat de la venue de Dionysos, dont les rites permettront aux mortels de retrouver une forme de contact avec le divin.

L'analyse - dont on n'a pu fournir ici qu'un résumé sommaire fournit du mythe une lecture originale dont la cohérence se révèle particulièrement satisfaisante pour l'esprit. L'A. puise l'essentiel de sa matière à penser dans les Dionysiaques de Nonnos. Évacuant d'emblée l'objection touchant le caractère tardif de cette source, M. Rocchi plaide en faveur de l'érudit de Panopolis dont l'œuvre foisonnante exacerbe des données constamment présentes dans la tradition mythologique et permet d'éclairer le sens de témoignages antérieurs trop lacunaires qui, sans cette confrontation, resteraient lettre morte. L'argument n'est pas toujours également convaincant dans ses applications, mais il faut reconnaître qu'un grand nombre de sources étudiées - et le matériel rassemblé est impressionnant - reçoit dans cette perspective un éclairage d'autant plus intéressant que l'étude d'autres épisodes mythiques par des auteurs aux méthodes différentes (Vernant, Rudhardt, entre autres) révèle des préoccupations identiques et qui semblent bien être inhérentes à la création mythologique des Grecs. Signalons enfin que l'abondante bibliographie aurait mérité un traitement indépendant des notes infrapaginales.

Vinciane PIRENNE-DELFORGE

\section{2) Actes de Colloques}

Cirene e i Libyi. Atti del simposio internazionale organizzato dalla Missione Archeologica Italiana e Cirene (Roma-Urbino, 13-16 aprile 1981), Roma, 'L'Erma' di Bretschneider, 1988, 547 p. (Quaderni di Archeologia della Libia, 12).

E. FABBRICOTTI, Divinità greche e divinità libie in rilievi di età ellenistica, p. 221-244.

M. LUNI, Il santuario rupestre libyo delle 'Imagine' a Slontoa (Cirenaica). Testimonianze della cultura libya in ambiente greco-romano : originalità e dipendenza, p. 415-458.

D. WHITE, Demeter Libyssa. Her Cyrenean Cult in Light of the Recent Excavations, p. 67-84. 